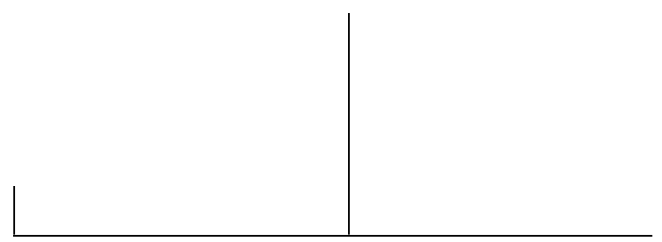

Rev. Latinoam. Psicopat. Fund., São Paulo, v. 13, n. 2, p. 352-355, junho 2010

Territórios do Acompanhamento Terapêutico

Susana Kuras de Mauer e Silvia Resnizky

Buenos Aires: Letra Viva, 2009, 206p.

\title{
Territórios do Acompanhamento Terapêutico
}

“A expansão territorial do acompanhamento terapêutico como prática clínica constitui o itinerário deste novo livro". Assim as autoras argentinas, Susana Kuras de Mauer e Silvia Resnizky, definem o percurso que traça seu mais novo livro, terceiro publicado por elas sobre o tema do Acompanhamento Terapêutico.

De fato, por expansão territorial podemos entender os mais diversos lugares que as autoras procuram abordar: a busca pelo lugar da profissão do acompanhante na sociedade contemporânea, legítimo e protegido pela lei; pelo lugar acadêmico como lugar de respaldo teórico que sustente a prática do AT, lugar pelo qual insistem com veemência as autoras; pelo lugar da escrita enquanto transmissão da experiência e produção de sentido; pelo lugar do acompanhante na clínica com seu paciente como um lugar que, prioritariamente, sustente uma posição de alteridade entre os dois (ou uma "outredade", palavra muito bem empregada para designar a entonação usada por elas quanto à importância da presença do outro para um sujeito que sofre).

O livro é dividido em três partes que se articulam entre si. 
A primeira parte trata de trazer recursos para uma teorização da clínica do Acompanhamento, coisa sempre interessante e instigante para os leitores que aspiram por uma ampliação de conhecimento sobre esta jovem clínica. As autoras definem eixos que nos norteiem para uma conceitualização da prática do AT. Estes eixos nos guiam em direção ao pensamento e aos seus principais questionamentos.

- Quais as diferenças entre aquilo que é visto como sadio e como doente na atualidade? Neste sentido, as autoras levam muito em conta a conjuntura social da América Latina de hoje, enfocando a omissão do Estado e a marginalização daquele sujeito que não se define como consumidor. Por meio deste enfoque, pontuam o grande paradoxo existente no fato de a circulação pelas ruas, por estes ditos "marginalizados", agravar ainda mais a sua condição de inexistência, paradoxo este que acentua a necessidade de se pensar na clínica do acompanhamento terapêutico enquanto clínica que promova outras formas de circulação social.

- Enfoques psicodinâmicos que colocam em vista uma abordagem múltipla do sofrimento psíquico, através de equipes multiprofissionais, apostando na relevância das relações vinculares, de forma a se considerar a transferência e a contratransferência.

- Criação de uma metapsicologia para o AT, o que significa revisitar a experiência clínica para tentar situá-la desde o ponto de vista tópico, dinâmico e econômico. Por tópico ou topologia, fala-se de espaço. O espaço de privilegiada potência de atuação do acompanhante é o entre-dois. Por dinâmico, propõem uma concentração no circuito pulsional e no lugar do AT tanto como "ao lado" das pulsões de vida quanto como testemunha-suporte das pulsões de morte. Finalmente, por econômico entende-se o AT como facilitador da ligação de energia livre em energia ligada a representações - sentido da simbolização.

- O lugar do Outro, desde uma perspectiva psicanalítica, tal como pensa Piera Aulagnier (uma das autoras mais abordadas no livro, além de Freud) que destaca a importância da cultura na conformação da subjetividade e dos vínculos. $\mathrm{O}$ vínculo é abordado aqui como algo que vai além do dualismo sujeito-objeto, de forma que suporte tudo aquilo que há de semelhanças, diferenças e de estranho entre dois sujeitos. O Outro como lugar do estranho dá um enfoque diferenciado para pensarmos as relações vinculares.

- Neste sentido, pensar entre a repetição e a novidade faz-nos acreditar no advento do novo como o grande norte da clínica do AT. Haveria a possibilidade de se sair da repetição e, através do acontecimento (elas aqui se referem a A. Badiou), fundar-se uma desarticulação na estrutura e o aparecimento de outra lógica de funcionamento psíquico. Há aqui uma critica às teorias estruturalistas do sujeito. Através da referência a Badiou, proclamam: o acontecimento explicita o inédito! 


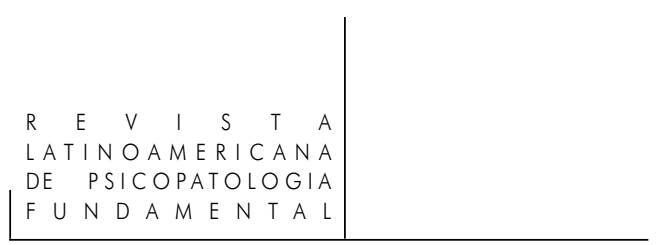

A concepção do inédito, enquanto além da repetição, é tema central no livro. Fazendo menção a Freud e sua proposta metapsicológica em "Além do princípio do prazer", as autoras propõem que se pense no lugar do AT enquanto o "outro que ampara". O desamparo é sublinhado como denominador comum aos campos de aplicação do acompanhamento terapêutico. Partindo de uma clínica das patologias do desamparo, nas quais reinaria a impossibilidade de escapar do desprazer inerente à repetição, as autoras propõem que pensemos o acompanhante terapêutico enquanto aquele que atua como "membrana protetora contra estímulos" vividos pelos pacientes como excessivamente traumáticos e aterrorizantes. O AT serviria de contorno, com um olhar que carrega e sustenta a disposição para o amparo. Este jogo do AT enquanto habitante de um território estrangeiro ao paciente (a realidade) ao mesmo tempo em que é um estranho que tem acesso a outro território, também estrangeiro ao paciente (seu sintoma), torna-o um íntimo, um "familiar na hora de tornar o desamparo menos doloroso". É a partir desta pluralidade de territórios que se pode tocar no inédito vivido com cada paciente.

Também a abordagem do conceito de resiliência, conceito trabalhado por outros autores argentinos como Rodríguez, Torres Délia e Vidal Inês, sustenta mais uma vez a proposta do outro como necessário ponto de apoio para a superação da adversidade. As autoras definem resiliência como a capacidade de recuperação da vida mental diante de situações adversas e traumáticas. A escolha do conceito de resiliência aponta para o acento na conjuntura social e sua articulação com o pensamento psicanalítico. Este compromisso do pensamento das autoras com a atualidade e suas formas de manifestação culturais e sintomáticas reincide por todo o livro. No quinto capítulo, a autora convidada, Susana Gutiérrez Posse, introduz o caráter de urgência enquanto demanda atual e, portanto, nova forma de clínica. Busca fundamentos para um trabalho multiprofissional com as chamadas "patologias do vazio" dentre as quais se encontram as adicções, os ataques de pânico, a anorexia e a violência contra o si mesmo, manifestada por cortes no próprio corpo e tentativas de suicídio. Todas elas são definidas através de um ponto comum: a linguagem do acting-out. A articulação entre o vazio do desejo, o vazio da tradição e da história, vazio da palavra, com a manifestação patológica através do ato e da demanda de urgência fazem deste capítulo ponto interessante a ser dialogado com o já abordado desamparo dos pacientes. São o vazio e o desamparo que, com todas as suas forças, demandam do AT criatividade em suas formas de intervenção.

A segunda parte do livro traz um recorte do acompanhamento terapêutico em diferentes momentos vitais. Quais as especificidades que constituem o acompanhamento na infância, na adolescência, na idade adulta e na terceira idade?

Ao falarem da infância e da adolescência, a perspectiva é o desvalimento infantil e a vulnerabilidade adolescente. Trazem a importância da trama familiar 
em questão e do AT inserido no contexto familiar. Os casos clínicos trazidos demonstram bem as diferentes funções que pode exercer um acompanhante, juntamente com citações de psicanalistas como Anna Freud, Bion e Winnicott que enriquecem as problematizações propostas. Desde casos em que o AT se constitui claramente em um ponto de apoio, em um guia para a família, até casos em que o diagnóstico em questão vai sendo esclarecido à medida que o trabalho da AT dentro da casa vai tomando corpo. "A valiosa coleta de dados do acompanhante, em relação à engenharia e à dinâmica familiar, constitui uma ferramenta-chave para o desenvolvimento do tratamento (...) O AT é testemunha de alguns dados da dinâmica familiar que a família não relata, porque nem sequer os registra como inconvenientes, e menos ainda como conflitivos."

A idade adulta e a velhice têm como tema comum a depressão e os necessários lutos a serem elaborados por parte dos pacientes. É posta em discussão a questão da depressão e da desesperança que hoje, mais do que nunca, vem desafiando os profissionais de saúde mental. A inserção do acompanhante enquanto presença disposta a facilitar estas elaborações é posta em perspectiva. A especificidade da velhice no contexto atual, no qual o idoso é desprovido do valor que tivera outrora traz à tona a questão do isolamento social do idoso e um questionamento em relação às políticas sociais vigentes. As autoras aqui clamam claramente por um lugar do AT enquanto um "agente de saúde dentro de um âmbito mais amplo de políticas sociais e de saúde que busquem gerar novas condições de vida".

A terceira parte do livro abarca percursos clínicos que ilustram e esclarecem aquilo que as autoras já vêm discutindo. Todo o livro - com este pano de fundo que enfatiza tanto a perspectiva psicanalítica do sujeito quanto as demandas sociais atuais - traz ao leitor psicanalista e AT a possibilidade de questionar suas práticas tendo em vista uma necessária abertura da clínica. E ao leitor que ainda não está familiarizado com a clínica do acompanhamento terapêutico, ler este livro o aproximará da amplitude que vem alcançando esta clínica, tanto em termos de formas de atuação como em termos de produção teórica, tudo isso com uma linguagem fácil, objetiva e envolvente.

\section{Cristiana Kehdi Gerab}

Psicóloga e Acompanhante Terapêutica; Terapeuta do Hospital-Dia do Instituto A Casa (São Paulo, SP, Brasil); Mestranda pelo Programa de Estudos Pós-Graduados em Psicologia Clínica da Pontifícia Universidade Católica de São Paulo - PUC-SP (São Paulo, SP, Brasil); Membro do Laboratório de Psicopatologia Fundamental (São Paulo, SP, Brasil).

Rua Mesquita, 561 - Aclimação 01544-010 São Paulo, SP, Brasil

Fone: (11) 99090799

e-mail: crisgerab@gmail.com 